\title{
Perfusion studies in relation to intestinal absorption
}

Traditional tolerance and balance studies can give at best only crude and indirect estimates of overall intestinal absorptive function in man. The introduction of long intestinal tubes ${ }^{1,2}$ provided a more direct method of studying absorption by the different regions of the gastrointestinal tract. Originally gut segments were isolated by balloons, solutions were introduced directly into the lumen, and unabsorbed material was recovered after a time interval ${ }^{3}, 4$. These methods were probably unreliable, because leakage of material past the balloons was likely and it was difficult or impossible to recover unabsorbed material rapidly and completely. The use of nonabsorbable markers in human intubation studies ${ }^{5}$ was a great advance, because it meant that quantitative recovery of unabsorbed material was no longer essential. The required properties of such markers are extremely important and have been discussed in detail elsewhere ${ }^{6,}$. At the present time, polyethylene glycol (PEG, Mwt 4,000) is the most widely used water-soluble marker available and has been subjected to critical assessment $^{8},{ }^{9}$.

Perfusion methods using transintestinal tubes and employing markers were introduced by Schedl and Clifton in $1961^{10}$, and multilumen tube methods were described by Fordtran and colleagues ${ }^{11}$ and later by Holdsworth and Dawson ${ }^{12}$. The principles and practical details of these methods are now well known and have been described in these and many subsequent papers (for example references 22-26, 41-43). It should be stressed that an open-ended steady-state system must be produced, in which concentrations of solute and marker are steady with respect to time but vary with distance down the intestinal segment. This is quite a different situation from that which obtains using closed loops, when concentration changes are related to time and the concentration is uniform throughout the loop. Only during the steady state can absorption rates of water and solute be calculated from the proximal infusion rate and the change in concentration of solute and marker between infusion and collection points.

A wide range of infusion rates has been used (usually 8-30 ml per minute) and, recently, there has been a tendency to criticize the faster rates as 'unphysiological'. However, no direct information is available about normal flow rates in different parts of the intestine after meals, although indirect assessment can be made. Thus, intubation studies in man indicate that, following a steak meal, approximately $2,000 \mathrm{ml}$ of fluid may enter the duodenum ${ }^{13}$. Assuming negligible absorption in the duodenum itself ${ }^{14}$, and that this fluid enters the upper jejunum within a period of three to four hours ${ }^{5}$, an approximate jejunal flow rate of $10 \mathrm{ml}$ per minute can be calculated. It is not necessarily a virtue to choose infusion rates of this magnitude, because it must be stressed that absorption from a steady-state perfusion system is very different from absorption from boli of food or fluid, which pass in both directions repeatedly during the more gradual onward progression of a meal. In the latter more strictly physiological situation the 
mucosal contact time is likely to be much greater. In this sense the perfusion system is almost as artificial as a closed loop or any other type of in vivo preparation. Purely experimental criteria such as solute concentration fall, length of gut perfused, and state of distension of gut $^{15}$, should be considered when deciding on a suitable infusion rate.

There are many difficulties and assumptions inherent in perfusion methodology. In practice, it is almost impossible to obtain a truly steady state. Such uncontrolled factors as proximal backwash of infused fluid, intrinsic gut motility ${ }^{16}$, and mucosal blood flow may be responsible for variations from moment to moment in segmental absorption rates. It is, therefore, essential that samples be collected over prolonged periods so as to minimize the effects of this variation. Equilibration periods of 30 to 60 minutes and collection periods of similar duration are recommended by various authors ${ }^{17},{ }^{18}$, the longer periods being required for slow infusion rates and long study segments. Such periods clearly limit the number of studies that can be performed on even the most cooperative subject and represent an important practical disadvantage of the method.

A major theoretical disadvantage of the simple double-lumen technique is that it makes no allowance for endogenous gut secretions which may, even in the fasting state, contaminate the study segment from above. Several modifications of the technique have been introduced recently in order to obviate this difficulty, but each has its disadvantages, and the practical importance of excluding contamination has never been demonstrated directly. The three-lumen tube method incorporates a mixing segment, which allows infused and contaminating fluids to mix and be sampled proximal to the study segment. This has been described and assessed as a means of studying water and electrolyte absorption ${ }^{17},{ }^{18}$. Significant contamination should underestimate rates of solute and water absorption, but a recent study, in which the two- and three-lumen methods have been compared $^{19}$, suggests that the former technique may not in fact underestimate sodium and water absorption rates in the normal jejunum. This implies that recent estimates of the mean flow rate of fasting intestinal contents ${ }^{18}$ are too high, and the methods used can be criticized ${ }^{19}$. A major practical disadvantage of the three-lumen tube is that solute and water may be absorbed by the mixing segment, so that the flow rate and composition of fluid entering the study segment cannot be controlled. For kinetic studies adequate control is essential, because both substrate concentration and flow rate may have marked effects on absorption (personal observations to be published and references 12,20 ). It is, therefore, difficult to design experiments and interpret results if this control is lacking.

Contamination can be effectively prevented by means of a proximal inflatable balloon ${ }^{21}$, and this method avoids the disadvantages of a mixing segment. It is probably more uncomfortable for the patient and, theoretically, it seems possible that inflation might affect gut motility and mucosal blood flow to such an extent that absorption rates are altered. If this is not the case, the ideal way of deciding about the importance of excluding fasting intestinal contents for any particular solute would probably be to compare perfusion periods in individual subjects with a proximal balloon inflated and deflated. To my knowledge, this has not been reported, although it is alluded to in reference 22 . Contamination is certainly unimportant as far as solutes such as glucose and most aminoacids are concerned. They are present in small 
or negligible concentration in fasting gut contents ${ }^{18,23}$ and are absorbed avidly. Solutes such as calcium and magnesium, although present in low concentration in intestinal contents, are absorbed relatively inefficiently and this means that even a small amount of contamination may be quite unacceptable, although there is no direct evidence to support this. All these factors must be taken into consideration when deciding on the best way to study absorption of any particular solute.

The great advantage of these methods is that quantitative and kinetic aspects of absorption can be studied. This may shed light on absorptive mechanisms and it enables comparison to be made with results of animal studies. However, kinetic data should not be overinterpreted. Studies of the absorption of several monosaccharides and aminoacids have shown that saturable mechanisms are involved and that there is competition for transport ${ }^{10,12,24}$. The hydrolysis and absorption of various disaccharides have been studied and analysed in a similar way ${ }^{25,26}$. A saturable relationship between luminal concentration of solute and its rate of absorption or hydrolysis can be considered analagous to the kinetics of enzyme-substrate interaction. All this means is that the substrate combines with and dissociates from some factor during transport and that this step limits the transport rate. This factor may be an enzyme or carrier involved in a specific transport process or it may be a purely physical phenomenon, such as adsorption to pores or membranes (for a full discussion, see reference 27). From reciprocal plots of absorption (or hydrolysis) rates and substrate concentration (Lineweaver-Burk ${ }^{28}$ ), certain constants can be derived: $v_{\max }$, which is the theoretical maximum absorption rate, and $\mathrm{Km}$, the substrate concentration required to half-saturate the absorption process. However, it must be emphasized that these absolute values may mean very little. There are large discrepancies between results obtained by different workers (for example, Table 2 of reference 29) and the values are probably affected by such factors as segment length and infusion rate, although this has not been specifically studied. Furthermore, these values bear little relationship to the corresponding figures obtained with in vitro intestinal preparations (for example, reference 30 pp 84, 123 and reference 24, table 5). In general, values for $\mathrm{Km}$ are much higher in intact man than in intestine in vitro, often by a factor of 10- or 20 -fold. A possible explanation for the high $\mathrm{Km}$ in man is that there are often appreciable gradients of luminal solute concentration down the segment, so that much of the mucosa is exposed to relatively low concentrations. Some authors have used the geometric mean of initial and final concentration ${ }^{24}$, rather than initial concentration, in their kinetic analyses, but even then the $\mathrm{Km}$ is many times greater than comparable figures in vitro. Furthermore, in rat perfusions in vivo ${ }^{20}$ high values of $\mathrm{Km}$ for glucose were found in spite of relatively small concentration gradients along the segment. A more probable explanation is that, in vivo, transported solute is rapidly removed by the blood stream so that it does not accumulate in tissue. This may mean that a much higher luminal concentration is required to saturate the rate-limiting step in transport. However, the values for different sugars and aminoacids may be usefully compared, provided the experimental conditions are constant ${ }^{12,24}$.

The regional absorption of fluid and electrolytes in intact man can probably only be studied in intubation methods, although other methods are available for studying absorption by the whole gut ${ }^{31,}{ }^{32}$. Isotopes of water 
and individual electrolytes have been used to measure both net transport and unidirectional fluxes in the small intestine ${ }^{11,22,33}$ and also in the colon $^{34,35}$. A recent report ${ }^{36}$ on the effects of antidiuretic hormone on sodium and water absorption shows that the state of hydration of the patient will affect the results and this should be borne in mind in studies of this kind.

Permeability properties of the intestine have been studied recently by perfusion methods and estimates of the size of the hypothetical water-filled pores have been calculated from these results. A widely quoted report ${ }^{37}$ describes a method which employed perfusions of hypertonic solutions of mannitol and other solutes. The rate of water entry into the lumen in response to osmotic gradients was used to calculate 'effective pore size' and, in a later paper $^{38}$, possible mechanisms of sodium absorption have been discussed in the light of these findings. Unfortunately, however, there is now some evidence that hypertonic solutions might damage the intestinal mucosa structurally and functionally ${ }^{39}$. Also, other absorption studies ${ }^{\mathbf{4 0}}$ suggest that the permeability properties of the intestinal mucosa may be somewhat different when the direction of bulk water flow is from lumen to blood. This problem is receiving much attention at present.

So far relatively few perfusion studies of pathological absorption processes have been reported. Sugar absorption ${ }^{41}$, aminoacid absorption ${ }^{42}$, folic acid absorption ${ }^{43}$, and the permeability properties of the jejunal mucosa ${ }^{44}$ have all been studied in patients with tropical and non-tropical sprue and some interesting observations have been made on infantile diarrhoea ${ }^{45}$. There is now direct evidence from perfusion studies that protein-calorie malnutrition in infants is associated with a reversible failure of absorption of glucose and some disaccharides ${ }^{46}$. Theoretically, it would be possible to study the absorption of any water-soluble solute in any pathological state using these methods. However, it must be admitted that the tests are cumbersome and time-consuming both for the patient and the investigator, and, furthermore, the normal ranges of most reported absorption rates are wide. The perfusion method is a valuable research tool, but is unlikely to be helpful in the diagnostic assessment of individual patients.

G. E. SLADEN

\section{REFERENCES}

${ }^{1}$ Abbott, W. O., and Miller, T. G. (1936). Intubation studies of the human small intestine III. A technic for the collection of pure intestinal secretion and for the study of intestinal absorption. J. Amer. med. Ass., 106, 16-18.

2Blankenhorn, D. H., Hirsch, J., and Ahrens, E. H., Jr (1955). Transintestinal intubation: technic for measurement of Gut length physiologic sampling at known loci. Proc. Soc. exp. Biol. (N. Y.), 88, 356-362.

${ }^{3}$ Abbott, W. O., Karr, W. G., and Miller, T. G. (1937). Intubation studies of the human small intestine VII. Factors concerned in absorption of glucose from the jejunum and ileum. Amer. J. dig. Dis., 4, 742-752.

'Groen, J. (1937). The absorption of hexoses from the upper part of the small intestine in man. J. clin. Invest., 16, 245-255.

'Borgström, B., Dahlqvist, A., Lundh, G., and Sjövall, J. (1957). Studies of intestinal digestion and absorption in the human. Ibid., 36, 1521-1536.

'Fordtran, J. S. (1966). Marker perfusion techniques for measuring intestinal absorption in man. Gastroenterology, $51,1089-1093$.

${ }^{7}$ Ingelfinger, F. J. (1964-65). Note on perfusion technique. In Year Book of Medicine, pp. 542-543. Year Book Medical Publisher, Chicago.

'Jacobson, E. D., Bondy, D. C., Broitman, S. A., and Fordtran, J. S. (1963). Validity of polyethylene glycol in estimating intestinal water volume. Gastroenterology, 44, 761-767.

${ }^{9}$ Schedl, H. P. (1966). Use of PEG and phenol red as unabsorbed indicators for intestinal absorption studies in man. Gut, 7, 159-163.

10 , and Clifton, J. A. (1961). Kinetics of intestinal absorption in man: normal subjects and patients with sprue. J. clin. Invest., 40, 1079 (abstr.).

${ }^{11}$ Fordtran, J. S., Levitan, R., Bikerman, V., Burrows, B. A., and Ingelfinger, F. J. (1961). The kinetics of water absorption in the human intestine. Trans. Ass. Amer. Phycns, 74, 195-206.

${ }^{12}$ Holdsworth, C. D., and Dawson, A. M. (1964). The absorption of monosaccharides in man. Clin. Sci., 27, 371-379. 
${ }^{13}$ Fordtran, J. S., and Locklear, T. W. (1966). Ionic constituents and osmolality of gastric and small intestinal fluids after eating. Amer. J. dig. Dis., n.s., 11, 503-521.

${ }^{14}$ Hindle, W., and Code, C. F. (1962). Some differences between duodenal and ileal sorption. Amer. J. Physiol., 203, 215-220.

${ }^{15}$ Dillard, R. L., Eastman, H., and Fordtran, J. S. (1965). Volume-flow relationships during the transport of fluid through the human small intestine. Gastroenterology, 49, 58-66.

${ }^{18}$ Groisser, V. W., and Farrar, J. T. (1962). Effect of intestinal motility on the absorption of sodium in man. Amer. J. dig. Dis., n.s., 7, 57-68.

${ }^{17}$ Cooper, H., Levitan, R., Fordtran, J. S., and Ingelfinger, F. J. (1966). A method for studying absorption of water and solute from the human small intestine. Gastroenterology, 50, 1-7.

${ }^{18}$ Whalen, G. E., Harris, J. A., Geenen, J. E., and Soergel, K. H. (1966). Sodium and water absorption from the human small intestine. The accuracy of the perfusion method. Ibid., 51, 975-984.

${ }^{19}$ Sladen, G. E., and Dawson, A. M. (1968). An evaluation of perfusion techniques in the study of water and electrolyte absorption in man: the problem of endogenous secretions. Gut, 9, 32-33.

${ }^{20}$ Dawson, A. M., and McMichael, H. B. (1968). The effect of flow rate on glucose absorption demonstrated by perfusion studies in rat jejunum in vivo. J. Physiol. (Lond.), 196, 32-33.

${ }^{21}$ Phillips, S. F., and Summerskill, W. H. J. (1966). Occlusion of the jejunum for intestinal perfusion in man. Mayo Clin. Proc., 41, 224-231.

22 _ _ - (1967). Water and electrolyte transport during maintenance of isotonicity in human jejunum. J. Lab. clin. Med., 70, 686-698.

${ }^{23}$ Adibi, S. A., and Gray, S. J. (1967). Intestinal absorption of essential amino acids in man. Gastroenterology, $52,837-845$.

${ }^{24}$ Fleshler, B., Butt, J. H., and Wismar, J. D. (1966). Absorption of glycine and L-alanine by the human jejunum. J. clin. Invest., 45, 1433-1441.

${ }^{25}$ Gray, G. M., and Ingelfinger, F. J. (1966). Intestinal absorption of sucrose in man: interrelation of hydrolysis and monosaccharide product absorption. Ibid., 45, 388-398.

${ }^{26}$ McMichael, H. B., Webb, J., and Dawson, A. M. (1967). The absorption of maltose and lactose in man. Clin. Sci., 33, 135-145.

${ }^{27}$ Fisher, R. B., and Parsons, D. S. (1953). Glucose movements across the wall of the rat small intestine. $J$. Physiol. (Lond.), 119, 210-223.

${ }^{28}$ Lineweaver, H., and Burk, D. (1934). Determination of enzyme dissociation constants. J. Amer. chem. Soc., $56,658-666$.

${ }^{29}$ Fordtran, J. S., and Ingelfinger, F. J. (1968). Absorption of water, electrolytes, and sugars from the human gut. In Handbook of Physiology, Section 6-Alimentary Canal. Volume III-Intestinal Absorption, pp 1457-1490. Edited by C. F. Code. American Physiological Society, Washington, DC.

${ }^{30}$ Wilson, T. H. (1962). Intestinal Absorption. Saunders, Philadelphia and London.

${ }^{31}$ Smirk, F. H. (1933). The rate of water absorption in man and the relationship of the water load in tissues to diuresis. J. Physiol. (Lond.), 78, 113-126.

${ }^{3}$ Love, A. H. G., Mitchell, T. G., and Phillips, R. A. (1968). Water and sodium absorption in the human intestine. Ibid., 195, 133-140.

${ }^{33}$ Whalen, G., Harris, J., and Soergel, K. (1965). Bidirectional flux of sodium and water in the human small intestine. Gastroenterology, 48, 859 (abstr.).

${ }^{34}$ Levitan, R., Fordtran, J. S., Burrows, B. A., and Ingelfinger, F. J. (1962). Water and salt absorption in the human colon. J. clin. Invest., 41, 1754-1759.

${ }^{36}$ Shields, R., Miles, J. B., and Gilbertson, C. (1968). Absorption and secretion of water and electrolytes by the intact colon in a patient with primary aldosteronism. Brit. med. J., 1, 93-96.

${ }^{36}$ Soergel, K. H., Whalen, G. E., Harris, J. A., and Geenen, J. E. (1968). Effect of antidiuretic hormone on human small intestinal water and solute transport. J. clin. Invest., 47, 1071-1082.

${ }^{37}$ Fordtran, J. S., Rector, F. C., Jr, Ewton, M. F., Soter, N., and Kinney, J. (1965). Permeability characteristics of the human small intestine. Ibid., 44, 1935-1944.

${ }^{38}+,-$, and Carter, N. W. (1968). The mechanisms of sodium absorption in the human small intestine. Ibid., 47, 884-900.

${ }^{30}$ Kameda, H., Abei, T., Nasrallah, S., and Iber, F. L. (1968). Functional and histological injury to intestinal mucosa produced by hypertonicity. Amer. J. Physiol., 214, 1090-1095.

"Sladen, G. E., and Dawson, A. M. (1968). Interrelationships between the absorptions of glucose, sodium and water by the normal human jejunum. Clin. Sci., in the press.

"Holdsworth, C. D., and Dawson, A. M. (1965). Glucose and fructose absorption in idiopathic steatorrhoea. Gut, 6, 387-391.

${ }^{42}$ Schedl, H.P., Pierce, C. E., Rider, A., and Clifton, J. A. (1968). Absorption of L-methionine from the human small intestine. J. clin. Invest., 47, 417-425.

${ }^{43}$ Hepner, G. W., Booth, C. C., Cowan, J., Hoff brand, A. V., and Mollin, D. L. (1968). Absorption of crystalline folic acid in man. Lancet, 2, 302-306.

A4Fordtran, J. S., Rector, F. C., Locklear, T. W., and Ewton, M. F. (1967). Water and solute movement in the small intestine of patients with sprue. J. clin. Invest., 46, 287-298.

${ }^{46}$ Torres-Pinedo, R., Rivera, C. L., and Fernández, S. (1966). Studies on infant diarrhea II. Absorption of glucose and net fluxes of water and sodium chloride in a segment of the jejunum. Ibid., 45, 1916-1922.

46James, W. P. T. (1968). Intestinal absorption in protein-calorie malnutrition. Lancet, 1, 333-335. 